\title{
Modified endoscopic vacuum therapy in the management of a duodenal transmural defect
}

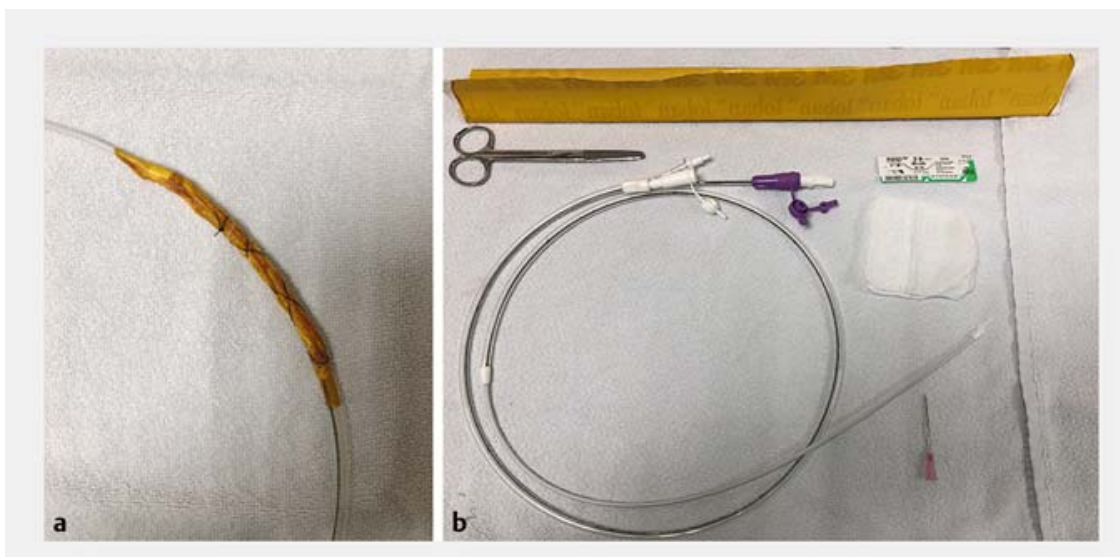

Fig. 1 Photographs showing: a the modified endoscopic vacuum therapy (EVT) device; b the items required to make the modified EVT device.

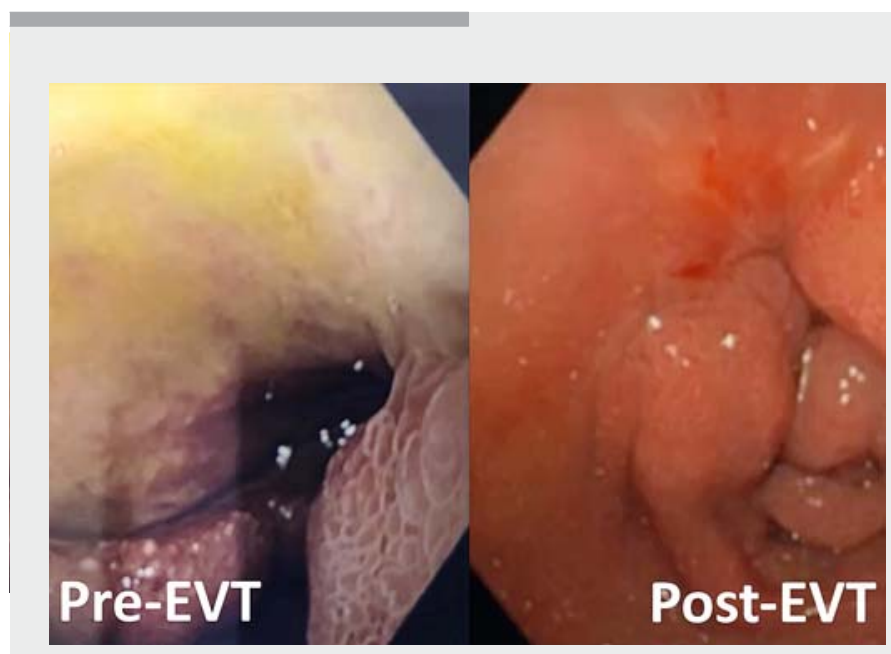

Video 1 Video showing how to make the modified endoscopic vacuum therapy device and its use, with subsequent exchanges performed, in the management of a patient with a duodenal transmural defect.

Gastrointestinal (GI) transmural defects are associated with high rates of morbidity and mortality $[1,2]$. Endoscopic vacuum therapy (EVT) has become a safe and effective tool for intraluminal treatment of these conditions, as it promotes changes in perfusion, microdeformation and macrodeformation of the tissue, and decreases bacterial contamination and local edema to facilitate healing. However, the high cost of the sponge system may limit widespread use of this technique [3]. In this video, we describe a cost-effective modified EVT for the treatment of transmural GI defects ( $>$ Fig. 1 a). The procedure is performed with the use of an antimicrobial incise drape, gauze, a nasogastric tube (NGT), and nylon su-

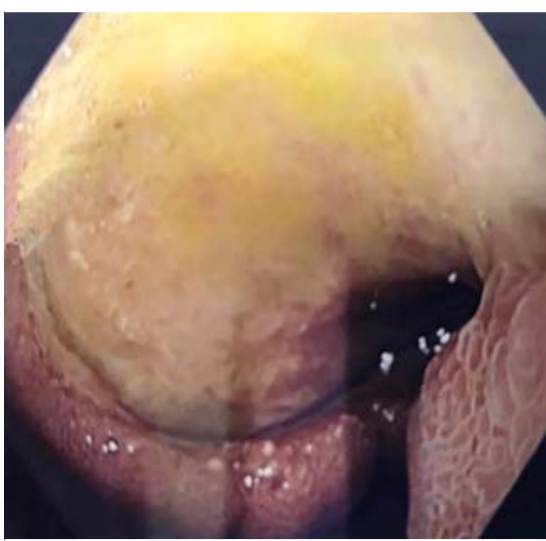

Fig. 2 Endoscopic image showing evidence of an ischemic ulcer in the duodenum with a contained perforation.

tures. First, the antimicrobial drape is cut to match the size of the fenestrated portion of the NGT. Several holes are then made in the drape using a needle. Next, the gauze is wrapped around the fenestrated portion of the NGT and this is covered in the antimicrobial drape. Finally, the suture is used to fix the gauze

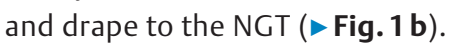

We report the use of this modified device in a 64-year-old man with cholangiocarcinoma who had undergone right hepatectomy and presented on post-operative day 30 with sepsis and melena. Esophagogastroduodenoscopy (EGD) and computed tomography (CT) scanning showed a transmural duodenal wall defect associated with a fluid collection ( Fig.2). Given the patient's clinical instability, it was decided that surgical therapy should be deferred owing to the high risk of mortality. Therefore, EVT was considered the best option for this patient. The patient was successfully treated with the modified EVT system ( $\triangleright$ Fig. 3; $>$ Video 1), with the first procedure being followed by four EVT system exchanges, and he was discharged from the hospital 24 days after his initial procedure. 

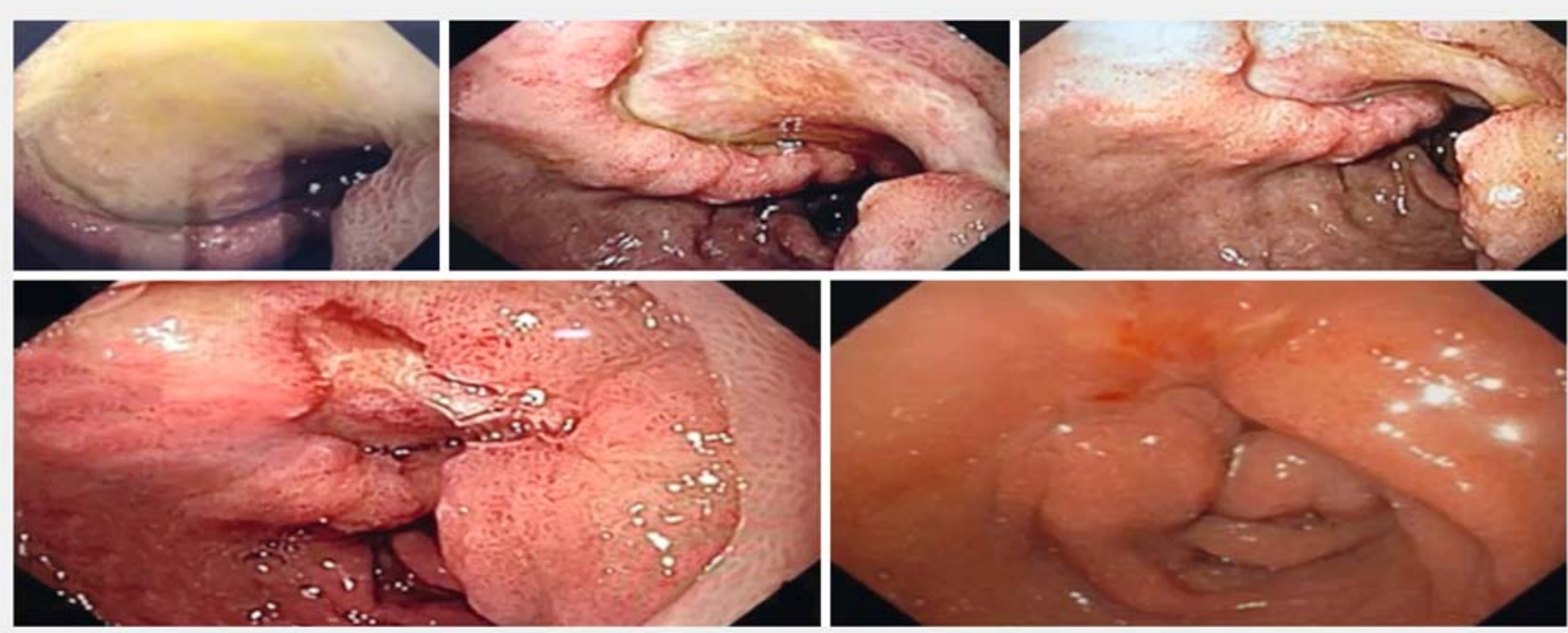

Fig. 3 Endoscopic images during the follow-up esophagogastroduodenoscopies showing progressive healing of the lesion.

This novel cost-effective modified endoscopic vacuum therapy is feasible and appears to be as safe and effective as the traditional sponge EVT system in the right clinical scenario.

Endoscopy_UCTN_Code_TTT_1AO_2AI

Competing interests

C.C. Thompson is a consultant for Boston Scientific, Medtronic, USGI Medical, Olympus, Apollo Endosurgery, Fractyl, and $\mathrm{Gl}$ Dynamics; has received research support from USGI Medical, Olympus, Apollo Endosurgery, Aspire Bariatrics, Spatz, and GI Dynamics; and has an ownership interest in GI Windows and EndoTAGSS. E.G.H. de Moura is a consultant for Boston Scientific and Olympus. The remaining authors declare that they have no conflict of interest.

The authors

Diogo Turiani Hourneaux de Moura', Epifânio Silvino do Monte Junior ${ }^{1}$, Kelly E. Hathorn ${ }^{2}$, Flaubert Sena de Medeiros ${ }^{1}$, Christopher C. Thompson², Eduardo Guimarães Hourneaux de Moura ${ }^{1}$

1 Endoscopy Unit, Gastrointestinal Department, Hospital das Clínicas da Faculdade de Medicina da Universidade de São Paulo, São Paulo, Brazil
2 Division of Gastroenterology, Hepatology and Endoscopy, Brigham and Women's Hospital, Harvard Medical School, Boston, Massachusetts, USA

\section{Corresponding author}

\section{Diogo Turiani Hourneaux de Moura, MD, PhD}

Endoscopy Unit - Gastrointestinal Department, Hospital das Clínicas da Faculdade de Medicina da Universidade de São Paulo, Rua Enéas de Carvalho Aguiar, 255, São Paulo, SP - 05679-065, Brazil dthmoura@hotmail.com

\section{References}

[1] de Moura DTH, Sachdev AH, Thompson CC. Endoscopic full-thickness defects and closure techniques. Curr Treat Options Gastroenterol 2018; 16: 386-405

[2] de Moura DTH, Brunaldi VO, Minata M et al. Endoscopic vacuum therapy for a large esophageal perforation after bariatric stent placement. VideoGIE 2018; 3: 346-348

[3] de Moura DTH, de Moura BFBH, Manfredi MA et al. Role of endoscopic vacuum therapy in the management of gastrointestinal transmural defects. World J Gastrointest Endosc 2019; 11: 329-344

\section{Bibliography}

Endoscopy 2021; 53: E17-E18

DOI 10.1055/a-1173-7282

ISSN 0013-726X

published online 29.5 .2020

(c) 2020. Thieme. All rights reserved.

Georg Thieme Verlag KG, Rüdigerstraße 14, 70469 Stuttgart, Germany

\section{ENDOSCOPY E-VIDEOS \\ https://eref.thieme.de/e-videos}

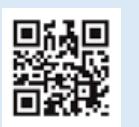

Endoscopy E-Videos is a free access online section, reporting on interesting cases and new techniques in gastroenterological endoscopy. All papers include a high quality video and all contributions are freely accessible online.

This section has its own submission website at

https://mc.manuscriptcentral.com/e-videos 